\title{
EDUCAÇÃO AMBIENTAL: UMA ANÁLISE DA POLUIÇÃO E CONTAMINAÇÃO DOS IGARAPÉS URBANOS NA CIDADE DE MANAUS
}

Francisco César Brito Vieira ${ }^{1}$

Eudenira Barbosa Batista Brito ${ }^{2}$

Ana Frazão Teixeira ${ }^{3}$

RESUMO: O presente trabalho tem o objetivo mostrar que as sociedades modernas são portadoras de conhecimentos que nem sempre sao trabalhados na educação ambiental, é de relevante contribuição as práticas e respeito ao meio ambiente. Os procedimentos metodológicos foram norteados pela pesquisa-açao a fim de possibilitar uma interação entre o pesquisador e objeto de estudo. A reflexão da pesquisa foi orientada pelo método hemeneutico dialetico, que enfatiza a intenção de interpretar e compreender o processo de construção da educação ambiental e os seus significados relacionados com o homem e o seu meio. Os dados foram coletados através das técnicas de observação direta, e do uso de entrevista semi-estruturada a fim de contextualizar e compreender os significados das informações obtidas. Neste trabalho buscou-se discutir a relação entre a educaçao ambiental e poluiçao dos igarapés de Manaus. E qual a relação entre ambiente e educaçao, impactos causados e minimizados a partir de uma consciencia preocupada com as questoes ambientais. Acreditamos que o presente trabalho é de profunda relevância para professores, pesquisadores e toda a classe acadêmica por suscitar uma questão que é sempre atual como questão ambiental.

PALAVRAS-CHAVE: Educação ambiental, Igarapés, Práticas e Poluição.

\footnotetext{
${ }^{1}$ Mestre em ensino de ciências na Amazônia pela Universidade do Estado do Amazonas - UEA, professor da rede pública municipal do 6 ao 9 ano.

${ }_{2}^{2}$ Acadêmica do 8 ano, do curso de administração pela Faculdade Anhanguera / UNIDERP.

3 Doutora em Química pela Universidade Federal do Amazonas, UFAM. Professora do programa de Pós Graduação e ensino de ciências na Amazônia pela Universidade do Estado do Amazonas - UEA. Orientadora do presente trabalho.
} 


\section{INTRODUÇÃO}

A educação ambiental ressalta peculiaridades sociais nas quais estão implícitas relações humanas. A questão ambiental está muito presente e ligada em todas as culturas além de proporcionar, interação, aprendizado, respeito e diálogo. "Esse saber vem de práticas comunitárias do saber ser, saber estar, saber dar uso, de um mundo que se reconhece na convivência e nas práticas". MUNOZ e LEFF (2003). A educação ambiental não pode ser ignorada, uma vez que ela se faz presente e acontece nas relações cotidianas, nos espaços não formais da comunidade, na escola, e tem o papel fundamental como agente de formação e transformação, valorizando os saberes e buscando um equilíbrio entre ser humano e natureza a partir da compreensão e sensibilização dos ecosistemas. Os educadores não podem ficar alheios as questões ambientais que as nossas cidades/escolas já estão enfrentando. A educação ambiental exerce um papel importante na escolarizacão, e preparação do estudante para a cidadania.

O crescimento populacional e econômico vem gerando grandes mudanças e alterações no ambiente. Em virtude dessas mudanças geradas pelo próprio homem, afetam-se o modo de vida no planeta e surgem conseqüências que influenciam todo um ecossistema.

Um ecossistema tem, geralmente, como fonte de energia externa, a luz solar, captada pela clorofila das plantas e acumulada, na forma de energia química, nas moléculas orgânicas que foram sintetizadas no processo fotossintético. (BRANCO, 2003, p. 24).

A partir daí desenvolve-se toda uma cadeia alimentar, constituída por animais herbívoros, carnívoros e os microorganismos, ou seja:

Um ecossistema deve conter organismos produtores, consumidores e decompositores, de modo a garantir uma contínua reciclagem de substâncias químicas. A cidade corresponde simplesmente à etapa consumidora do sistema. Não há reciclagem, não há o retorno dos componentes químicos, uma vez que os resíduos da cidade são soterrados em aterros sanitários de lixo ou simplesmente 


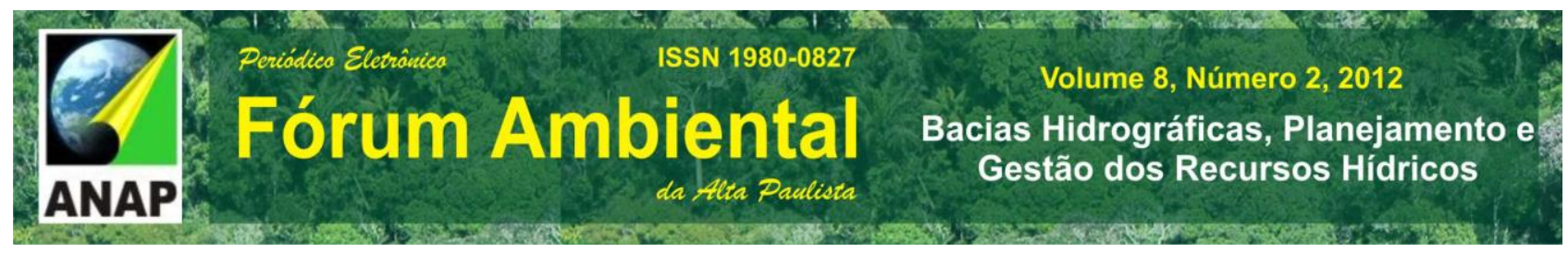

lançados ao solo, aos rios, na forma de esgotos e na atmosfera. (BRANCO, 1997, p. 77).

Um fluxo contínuo de materiais que provém de áreas externas à cidade, são aí consumidas, gerando subprodutos que se acumulam no meio ambiente e não retornam às áreas de produção. Em conseqüência disso temos de um lado a poluição cada vez maior da água, do ar e do solo das cidades. (BRANCO, 1997, p. 77).

Branco (1997, p. 78), define poluição como a colocação de energia e matéria no lugar errado. Ao se colocar certa quantidade de matéria ou energia que o ambiente não é capaz de assimilar, fica sobrecarregado, seu equilíbrio se desfaz, e se altera completamente sua composição.

A aceleração da urbanização faz com que aumente cada vez mais o volume retirado dos rios para abastecer residências e indústrias. $O$ crescimento das cidades causa também outras pressões sobre as reservas hídricas: o aumento do volume de resíduos sólidos (lixo) e o despejo de resíduos industriais e domésticos sem tratamento que contribui para poluir córregos e rios e entupir as vias de drenagens das cidades, e a ocupação irregular do solo, que compromete os mananciais. (ATUALIDADES, 2009, p.38).

A distribuição desigual dos mananciais, justamente nas áreas de maior demanda por água, seja porque concentram grandes contingentes populacionais ou intensa atividade econômica, têm grande parte de seus recursos hídricos comprometidos pela poluição de origem doméstica e/ou industrial e agrícola (HIRANO, 2001, p. 13).

Para Canivatto (2003, p. 67-68), cada pessoa ao consumir em média duzentos litros de água por dia, converte cento e cinquenta litros em esgoto e os cinquenta litros restantes podem voltar à atmosfera pela evaporação ou infiltrar-se no solo. Os esgotos são também chamados de resíduos líquidos, por possuir na sua composição mais de $99 \%$ de água. Os esgotos possuem alta concentração de substancias orgânicas resultantes de restos de comidas, fezes, sabão e outros produtos usados nas residências. Esses compostos ao chegarem aos rios servem de alimentos aos organismos aeróbicos (que dependem do oxigênio para viver). 


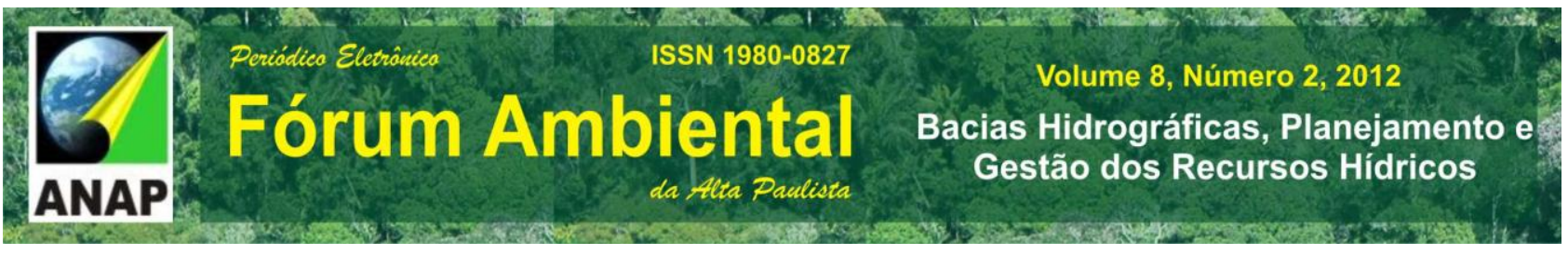

A composição dos resíduos industriais é diversificada, dependendo do processo de fabricação do produto. Normalmente as indústrias que produzem alimentos geram esgotos com altíssima concentração de matérias orgânicas, que serão consumidas avidamente pelas bactérias aeróbicas, que se multiplicam rapidamente, consomem 0 oxigênio disponível na água, provocando a morte de peixes. (CANIVATTO, p. 68, 69, 2003).

O consumo de oxigênio necessário para que todas as substâncias orgânicas presentes em determinado trecho de rio sejam assimiladas pelas bactérias pode ser determinado por laboratório. Essa medida, chamada de Demanda Bioquímica de Oxigênio, ou DBO, é um dos principais métodos para avaliar a poluição das águas (CANIVATTO, p. 68, 2003).

Os detritos gerados nos hospitais, conforme Canivatto (2003, p. 77), contêm frascos de medicamento, algodão, agulhas de injeção e outros objetos que oferecem maior risco de contaminação por organismos patogênicos.

As estatísticas internacionais apontam que cerca de $80 \%$ das doenças e mais de $30 \%$ das mortes em países em desenvolvimento são causadas pelo consumo de água contaminada (HIRANO, 2001, p.18).

Um trabalho desenvolvido por Hirano (2001, p. 18), para a Organização Pan Americana da Saúde destaca-se que para a garantia de que água seja um elemento fundamental na promoção da saúde e bem-estar das populações é preciso prever não somente a qualidade, mas também a regularidade em quantidades adequadas à satisfação das necessidades humanas. Pois, em estudos relacionando quantidade de água consumida e incidência de diarréia, foram encontradas ligações positivas na maioria dos casos.

\section{Discussões a respeito da Educação Ambiental}

Os Parâmetros Curriculares Nacionais de Ciências Naturais (2000), para o Ensino Fundamental apontam questões relacionadas ao Meio Ambiente, tendo como um dos objetivos que os alunos devem "perceber-se integrante, dependente e agente 
transformador do ambiente, identificando seus elementos e as interações entre eles, contribuindo ativamente para a melhoria do meio ambiente".

Já pela Lei 9795/99, conforme o Art. 11, "a dimensão ambiental deve constar dos currículos de formação de professores, em todos os níveis e em todas as disciplinas". Além disso, o Parágrafo único deixa explícito que "os professores em atividade devem receber formação complementar em suas áreas de atuação, com o propósito de atender adequadamente ao cumprimento dos princípios e objetivos da Política Nacional de Educação Ambiental".

Conforme os dados do último Censo do INEP/MEC, ações em EA já estão incorporadas em praticamente $95 \%$ das escolas no Brasil. Teríamos então sua institucionalização, mas é evidente a fragilização das práticas (GUIMARÃES, 2004, apud GUERRA e ORSI).

Persiste a contradição entre discurso e prática apesar do educador manifestar desejo de efetuar uma EA emancipatória e crítica articulada com o exercício da cidadania. Sua prática, na maioria das vezes, continua respaldada na "pedagogia bancária", na fragmentação do conhecimento, ou em uma concepção de interdisciplinaridade iniciante, uma perspectiva focada na mudança de comportamentos do indivíduo. Nela, o conteúdo e estratégias de ensino têm uma finalidade conteudista e informativa, meramente de transmissão do conhecimento do professor para o aluno, realizado em atividades pontuais descontextualizadas da realidade socioambiental (GUERRA \& TAGLIEBER, 2007)

\section{Igarapés na cidade de Manaus}

O espaço urbano da cidade de Manaus é drenado por quatro bacias hidrográficas, duas encontram-se integralmente dentro da cidade - do igarapé de São Raimundo e do igarapé do Educandos - e duas parcialmente inseridas na malha urbana - do igarapé do Tarumã-Açú e do rio Puraquequara, (PROJETO GEO CIDADES, 2002).

Essas duas últimas bacias são os limites naturais da expansão urbana de Manaus, o rio Puraquequara é o limite pela parte oriental e o curso inferior do igarapé Tarumã-Açú é o limite pela parte ocidental. 
Definição de igarapé - Igarapé é um termo indígena que significa "caminho de canoa", igara = canoa e pé $=$ trilha, caminho, (GUERRA, ANTÔNIO, 1975). Igarapés são pequenos cursos d'água que segundo Sioli (1991) podem ser de águas brancas que foram observados na região do Acre, os de águas claras dominam a região central da Amazônia, típicos de terra firme e os de águas pretas que provêm de áreas com solo arenoso, vegetação peculiar diferente da floresta alta, as "caatingas amazônicas", chamadas campinas observados pelo autor nas proximidades de Manaus, no igarapé do Tarumanzinho.

A elevada pluviosidade na Amazônia contribui para a existência de uma densa rede de igarapés que, oriundos dos sedimentos arenosos terciários, apresentam leitos constituídos praticamente de areia ou pedras com pH baixo e água ácida (SILVA, 2005).

\section{Integram a bacia do igarapé de São Raimundo:}

Igarapé do Mindú - principal tributário do São Raimundo tem uma de suas nascentes localizada no bairro Jorge Teixeira, na Zona Leste, próximo ao Jardim Botânico da Reserva Ducke. Cruza a cidade no sentido nordeste-sudoeste, percorrendo e delimitando inúmeros bairros, como Jorge Teixeira, Tancredo Neves, Cidade Nova, Aleixo, Parque 10 de Novembro, N. S. das Graças e São Geraldo.

Igarapé dos Franceses - localizado na Zona Centro-oeste, é um dos principais contribuintes da bacia. Drena os bairros de Alvorada I, Alvorada II, D. Pedro I e D. Pedro II;

Igarapé do Bindá - nasce na Zona Norte e percorre os bairros de Cidade Nova, Parque Dez e União;

Igarapé de Manaus - localizado próximo à área central de Manaus, corta importantes vias de acesso ao centro e, a exemplo do que ocorre com os igarapés da Cachoeirinha e do Mestre Chico, sofre as conseqüências das cheias dos rios Negro e Amazonas. 


\section{A bacia do igarapé do Educandos é integrada por:}

Igarapé do Quarenta - é um dos principais tributários da bacia do Educandos, sua nascente está localizada no bairro Armando Mendes, onde ainda se encontra vegetação típica de mata primária e apresenta cor marrom-escura, com forte odor. De sua nascente até a confluência com o igarapé do Educandos, passa pelo distrito industrial onde recebe efluentes das indústrias, esgotos e lixo domésticos, por atravessar uma vasta área residencial.

Percorre áreas urbanas ocupadas, como o Distrito Industrial da SUFRAMA e os bairros do Coroado e Japiim. No igarapé do Quarenta, manifestam-se vários níveis de degradação ambiental produzidos, de um lado pelos resíduos químicos oriundos das indústrias e, de outro, pelo adensamento populacional, devido a ausência de uma infraestrutura urbana e de políticas públicas que impeçam o lançamento de lixo e melhore o sistema de esgoto no igarapé.

Igarapé da Cachoeirinha - abrange os bairros da Cachoeirinha, Petrópolis, Raiz e São Francisco. O igarapé atravessa vales que estão sujeitos à inundação, principalmente nos meses de janeiro a junho;

Igarapé do Mestre Chico - localizado próximo à área central de Manaus abrange parte do bairro da Cachoeirinha e cruza vias importantes de acesso ao centro da cidade até desaguar no Educandos. Por suas características, também está sujeito a inundações.

Os tributários do igarapé Tarumã-Açú pela margem esquerda, localizados dentro da área urbana, são:

Igarapé Leão - nasce ao norte da Reserva Ducke e seu percurso corresponde a um trecho do limite setentrional da área de transição, definida pelo novo perímetro urbano de Manaus; 
Igarapé do Mariano - tem algumas de suas nascentes localizadas dentro da Reserva Ducke e seu talvegue, entre a reserva e sua embocadura, constitui o limite norte da área urbana e do bairro do Tarumã;

Igarapé do Bolívia - nasce dentro da Reserva Ducke, cruza a Rodovia AM-10 e corta áreas em processo de ocupação na zona norte da cidade, assim como o bairro do Tarumã. Além de receber água servida ao longo da área por onde passa encontra-se contaminado pelos produtos que são carreados da lixeira pública municipal, inclusive o lençol freático.

Igarapé do Tarumanzinho - integralmente localizado dentro do Bairro do Tarumã.

\section{CRESCIMENTO E PROBLEMAS AMBIENTAIS}

Com a da implantação da Zona Franca de Manaus na década de 1960, a cidade cresceu de forma desorganizada e sem planejamento, acarretando sérios problemas ambientais e sociais, sobretudo no que diz respeito ao crescimento populacional. A ocupação desordenada de áreas próximas aos igarapés imprimiu um impacto negativo, com a destruição das coberturas vegetais, à poluição dos corpos d'água e à deficiência de saneamento básico.

Com a pressão demográfica centenas de moradias estão localizadas em faixas marginais dos cursos d'água, áreas consideradas como de preservação permanente. A maior parte destas moradias corresponde a palafitas precárias, implantadas sobre espelhos d'água ou em áreas sujeitas a inundações. Muitas constituem construções de alvenaria, localizadas em talvegues secos de antigos igarapés ou em terrenos não alagadiços. As populações sem poder aquisitivo se apropriaram das calhas dos igarapés da cidade de Manaus, em que:

Seguiu-se simultaneamente à densidade demográfica a ocupação das margens dos pequenos cursos d'água, as matas ciliares foram sendo substituídas pelas casas de madeira, desprotegendo o solo pela sua forma inadequada de construção e ausência de infra-estrutura urbana nas áreas externas entre as 
casas separadas por vielas, seguiu-se o processo de assoreamento dos igarapés pela deposição de despejo dos esgotos sem tratamento e o lixo não recolhido transformaram os igarapés em esgotos de águas fétidas, configurando-se um quadro crítico na paisagem. (SILVA, 2005)

Os poucos igarapés remanescentes que cortam o sitio urbano encontram-se poluídos, impróprios à recreação, como foi na década de 1970 o balneário do Parque Dez, que reunia nos finais de semanas uma grande parcela da população manauara para banhar-se nas suas águas límpidas.

Hoje, constitui-se com os demais, como o igarapé do Quarenta, da Cachoeira Grande, entre outros, em verdadeiros esgotos a céu aberto devido à carga de poluição, exalando odor característico de um ambiente alterado por processos antropogênicos. Os dejetos deveriam ser tratados e lançados no rio Negro, porém, em razão das condições atuais do sistema, muitas indústrias estão lançando seus esgotos nas redes de drenagem e nos cursos d'água, principalmente no Igarapé do Quarenta (Águas do Amazonas, 2001).

\section{COMBATENDO A POLUIÇAO DAS ÁGUAS}

Chamamos de água poluída a que:

1. Apresenta cheiro forte provocado pelas substâncias químicas;

2. Apresenta cores variadas, como amarelo, verde ou marrom;

3. Possui gosto diferente por causa das substâncias tóxicas.

As substâncias que se misturam na água são chamadas de agentes poluentes que fazem muito mal aos seres vivos. Veja alguns agentes poluentes das águas de nossos igarapés:

1. Esgotos da cidade, eliminados em igarapés e rios;

2. Detritos domésticos, lançados nos igarapés e que são carreados até os rios;

3. Elementos sólidos, líquidos e gasosos.

4. Óleo e lixo que os barcos, lanchas e navios lançam nos rios. 
São muito comuns as pessoas confundirem água poluída com água contaminada, razão pela qual vamos explicar cada uma delas.

Água Contaminada: é aquela que transmite doenças, pois além de conter microorganismos, restos de animais, larvas e ovos de vermes.

Água Poluída: é aquela que tem cheiro forte, cor bem escura, que alterou suas características naturais, isto é, deixou de ser pura e saudável para os seres vivos.

A poluição da água traz conseqüências muito graves aos seres vivos. As principais são:

1. Substâncias tóxicas lançadas nas águas pelas indústrias atingem os animais e vegetais aquáticos, chegando a matá-los;

2. Os animais e vegetais aquáticos atingidos contaminam o homem;

3. Os esgotos da cidade podem lançar nos igarapés e rios seres vivos causadores de doenças.

4.

Principais doenças transmitidas diretamente da água

\begin{tabular}{|l|l|l|}
\hline \multicolumn{1}{|c|}{ Doenças } & \multicolumn{1}{|c|}{ Agente causador } & \multicolumn{1}{c|}{ Sintomas } \\
\hline Cólera & Víbrio cholera & $\begin{array}{l}\text { Diarréia abundante, vômitos ocasionais, } \\
\text { rápida desidratação, acidose, câimbras } \\
\text { musculares e colapso respiratório }\end{array}$ \\
\hline Amebíase & Entamoeba histolytica & $\begin{array}{l}\text { Disenteria aguda, com febre, calafrios e } \\
\text { diarréia sanguinoletenta. }\end{array}$ \\
\hline Gastrenterite Viral & Rota vírus & $\begin{array}{l}\text { Diarréia, vômitos, levando à desidratação } \\
\text { grave. }\end{array}$ \\
\hline Hepatite & Vírus de Hepatite A & Febre, mal-estar geral, falta de apetite. \\
\hline Desinteira Bacilar & Bactéria Shigella & Fezes com sangue e pus, vômitos e cólicas. \\
\hline
\end{tabular}

Outros males são causados por ingestão de água contaminada, precariamente tratada ou em contato com a pele. 
Uma série de doenças pode ser associada à água, seja em decorrência de sua contaminação por excreção humana ou de outros animais, seja pela presença de substâncias químicas nocivas à saúde humana.

Para evitar e combater a poluição dos nossos igarapés e rios, não precisa acabar com as fábricas e indústrias, precisamos tomar algumas medidas básicas e simples como:

1. Colocar filtros nas fábricas e em indústrias;

2. Tratar os esgotos para evitar que contaminem os igarapés e rios;

3. Evitar jogar lixo ou material reciclável nos igarapés e rios;

4. Conduzir toda a água utilizada pela população para uma estação de tratamento.

\section{AGUAPÉS DESPOLUEM E DESCONTAMINAM RIOS E LAGOS}

O aguapé é uma planta muito abundante em nossa região e pode ser vista num bom trecho nos igarapés do quarenta (entre a rua Silves até a ponte de educandos), do Sao Raimundo e de Manaus, essa planta pode ajudar a limpar rios e lagos poluídos ou contaminados. Trata-se de um vegetal nativo de regiões tropicais. Sua adaptação é muito fácil em diversos ambientes e prolifera em quase todo o território brasileiro. O aguapé já foi chamado de "praga-d'âgua". No Brasil, essa planta é natural da Amazônia e do Pantanal.

Esse vegetal é um recurso acessível e barato para o tratamento de rios e lagos. Estudos comprovam que o aguapé tem a propriedade de assimilar, através de suas raízes, substâncias poluidoras, especialmente metais pesados (chumbo, mercúrio, zinco, cobre); os metais pesados, venenosos, são lançados na água por indústrias químicas, localizadas no parque industrial de Manaus, PIM.

As raízes do aguapé assimilam e retiram da água também os nutrientes que desencadeiam o desenvolvimento de bactérias patogênicas (que causam doenças). 
está sendo adotado desde 1985 na usina Costa Pinto (no mesmo rio Piracicaba). Em 1994 foi empregado em Ubatuba, para limpar a estação de esgotos daquela cidade. (BARROS e PAULINO, 2003, p.221)

\section{CONSIDERAÇOES FINAIS}

A preservação dos igarapés, nascentes e mananciais, depende da forma de trabalhar uma educação ambiental voltada a levar o estudante de encontro a novos conhecimentos, mostrando a situação de degradação causada pela sociedade. Professores e estudantes precisam trabalhar em torno de projetos, agregando novos costumes e práticas à sua cultura ambiental, não implica na extinção dos saberes, apenas aceitar as modificações que a atualidade requer, criando uma nova tendência de cultura e preservação, onde surgem novas perspectivas de transformação social através da formação ambiental Pois se espera que essas atrações naturais possam ser preservadas e que esse meio ambiente possa contribuir, enquanto fonte de estudo e pesquisa, para a qualidade de vida de populações locais. Em oportunidades que permitam experiências, tanto ambientais como culturais.

Diante disso percebe-se que a construção de projetos e parcerias voltados para a prática da educação ambiental é necessária para que possam dar respaldo aos interesses da comunidade e ocorram significativas trocas.

O reconhecimento e a valorização das práticas devem caminhar sempre juntos, numa interação comunidade e sociedade, possibilitando a população à preservação do meio ambiente onde vivem.

Diante desses fatos, conclui-se que preservar o meio ambiente é proporcionar uma relação de equilíbrio ser humano e natureza, é a única maneira de cuidar da sobrevivência da espécie, da qualidade de vida e da dignidade das pessoas. É a oportunidade que temos, todos nós que vivemos em Manaus, de demonstrar que é possível conviver em harmonia com a natureza sem destruir os recursos naturais. Conservar esses mananciais é mais que um compromisso, é demonstrar a capacidade e competência da razão de existir. 


\section{REFERÊNCIAS}

BARROS, Carlos. PAULINO, Wilson. Ciências - O Ambiente. São Paulo: Ática, 2003.

BRANCO, Samuel Murgel. O Meio Ambiente em Debate. 26 ed. São Paulo: Moderna, 1997.

CANIVATTO, Vilma Maria. Saneamento Básico: fonte de saúde e bem estar. 2. ed. São Paulo: Moderna, 2003.

CURSO DE EDUCAÇÃO AMBIENTAL: Curso Ambiental II: História do Amazonas Trajetória e curiosidades dos Igarapés de Manaus. SEMED. 2007.

HIRANO, Cecy Oliveira. Programa de Saneamento Básico e Cidadania. Organização Pan Americana da Saúde. Divisão de Saúde e Ambiente. Washington, 2001.

MANAUS, Secretaria Municipal de Meio Ambiente, Secretaria Municipal de Obras, Saneamento e Habitação. Recuperação ambiental e requalificação social e urbanística no Igarapé do Mindú, Manaus, Amazonas. Manaus: 2007.

MENDES FILHO, Ivanhoé; SCHERER, Elenise. Injustiça Ambiental em Manaus. Disponível em: http://www.anppas.org.br/encontro anual/encontro2/GT/GT17/gt17 elenise.pdf (Acesso em 03.08.2009).

MUNOZ, Maritza Gómez. LEFF, Enrique (org). A Complexidade Ambiental. São Paulo: Cortez, 2003

PROJETO GEO CIDADES. Relatório ambiental urbano integrado: informe GEO. Rio de Janeiro: consórcio parceria 21, 2002. 188 p.

REIGOTA, Marcos. O que é Educação Ambiental. São Paulo: Brasiliense, 2006.

SANTOS, Aparecido Gomes dos. BENTO, Antônio Henrique. Observando a Natureza. Manaus: EDUA, 2007.

SILVEIRA, leda. A Geografia da gente: água, meio ambiente e paisagem. São Paulo: Ática, 2003.

VENTURALI, Thereza. Água: Desperdício, mau uso e poluição das fontes ameaçam a humanidade com o fantasma da sede. Revista Atualidades Vestibular + ENEM. 9. ed. Editora Abril, 2009. 